\title{
Social Class versus Cultural Identity as Factors in the Residential Segregation of Ethnic Groups in Toronto, Montreal and Vancouver for 2001
}

\author{
T.R.Balakrishnan \\ Paul Maxim \\ Rozzet Jurdi \\ Population Studies Centre \\ University of Western Ontario \\ London, Ontario, Canada
}

\begin{abstract}
This article examines the relevance of the spatial assimilation model in understanding residential segregation of ethnic groups in the three largest gateway cities of Canada. Using data from the census of 2001 it finds that while the model may have worked for the European groups they are less applicable to the visible minorities such as the Chinese, South Asians and Blacks. Residential segregation reduces with generation for the European groups but not for the visible minorities. Canadian patterns seem to be different from that seen in the United States. Many visible minority groups maintain their concentration levels even in the suburbs. The findings seem to indicate that cultural preferences may be just as important as social class in the residential choices of visible minority groups.
\end{abstract}

Key Words: Cultural identity, residential segregation, visible minorities 
T. R. Balakrishnan, Paul Maxim and Rozzet Jurdi

\section{Résumé}

Cet article examine la pertinence du modèle d'assimilation spatiale dans la compréhension de la ségrégation résidentielle des groupes ethniques dans les trois villes «portes d'entrée» les plus importantes du Canada. En s'appuyant sure les données du Recensement de 2001, cet article démontre que même si ce modèle ait pu fonctionner pour les groupes européens, il ne s'applique pas autant aux groupes tels que les Chinois, les Sud-Asiatiques et les Noirs. La ségrégation résidentielle diminue avec les générations chez les groupes européens mais ceci n'est pas le cas chez les groupes de minorités visibles. Les tendances canadiennes semblent être différentes que celles observées aux ÉtatsUnis. Beaucoup de groupes de minorités visibles maintiennent leur niveau de concentration même dans les banlieues. Les études menées semblent indiquer que la préférence culturelle pourrait jouer un rôle aussi important que la classe sociale dans les choix de résidence que prennent les minorités visibles.

Mots-clés: Identité culturelle, ségrégation résidentielle, minorités visibles

\section{Introduction}

The past four decades have seen a fundamental change in the composition of Canada's population by ethnicity. While immigrants from the Western Europe predominated before the 1960s, in the 1960s and 1970s most immigrants were primarily from southern Europe. Since then however, people from the thirdworld countries have formed the majority of immigrants. In the most recent decade 1991-2000, about 1.8 million immigrants and refugees arrived in Canada , the highest number for any decade. More than two thirds of them were socalled visible minorities, mostly from Asia, but also significant numbers from the Caribbean, Latin American and African countries. While the proportion of population with western European origins have been going down, the proportion of visible minorities have been going up drastically. Canada's visible minority population has tripled since 1981. In 1981 there were 1.1 million people classified as members of a visible minority while there were 3.2 million in 2001, 
Social Class versus Cultural Identity as Factors in the Residential Segregation

of Ethnic Groups in Toronto, Montreal and Vancouver for 2001

about 11.2 percent of the total. Canada has never been more ethnically diverse than it is now (Statistics Canada 2003).

This drastic change in the ethnic composition of immigrants to Canada and their places of destination on arrival has resulted in a renewed interest in their residential patterns. Unlike the early European settlers who often went to small towns and rural areas across the length and breadth of Canada, new immigrants who are primarily visible minorities choose to reside in the large metropolitan areas and have distinct preferences for certain provinces. Three quarters of the visible minority population lives in Ontario or British Columbia, most of them in Toronto or Vancouver. In Toronto, the visible minority population increased from 13.6 percent in 1981 to 36.8 percent in 2001 and in Vancouver from 13.9 percent to 36.9 percent in the same period. In contrast, the visible minorities formed only 0.8 percent of the population in Newfoundland. Within cities there has also been considerable changes in settlement patterns. This is because the ethnic neighbourhoods change in size, location and character as a consequence of immigration patterns. The rapid growth of ethnic and racial minorities through immigration can increase their concentration and segregation from the majority groups. For example, visible minority neighbourhoods have increased rapidly in the gateway cities of Toronto, Montreal and Vancouver in the past two decades. Defining a "visible minority neighbourhood" as a census tract where at least $30 \%$ of its population is from a particular visible minority, one study found that the numbers increased from 6 in 1981, to 77 in 1991, to 254 in 2001 in the three cities combined (Hou and Picot 2004).

Conventional wisdom has been that residential segregation has more negative consequences than positive ones. It is believed to promote segregation in other social institutions, leading to various forms of discrimination. Residential segregation can affect linguistic assimilation, educational facilities, and occupational mobility. Because residential segregation increases the visibility of a racial or ethnic group, it can sharpen prejudices and discrimination by the dominant groups. Many of the problems of Blacks in the American cities have been attributed to their residential segregation (Massey and Denton 1993). The situation in Canada may be different. Some writers have suggested that there may be positive consequences of residential segregation in the retention of heritage language and cultural identity (Lieberson 1970; Joy 1972; Balakrishnan 2000). Since spatial isolation is seen as a powerful indicator of a group's social position in the community, research studies continue to be done to understand the causes and consequences of residential segregation and in its changes over time. 


\section{Theoretical Framework}

Three hypotheses have been advanced and tested to explain the trends and changes in residential segregation (Balakrishnan 1982).The first, which can be called the "social class hypothesis" states that ethnic residential segregation is a reflection of social class differences among the ethnic groups. Immigrants who are forced to live in the poorer areas of a city due to a lack of resources will move to better areas as their socio-economic conditions improve. This is often referred to as the spatial assimilation model. Starting with the early Chicago School work of Burgess, many others have elaborated and tested the model which has somewhat withstood the passage of time in urban studies (Burgess 1967; Lieberson 1980; Massey and Duncan 1985). In the Canadian scene, there have been limited studies to show that segregation does decrease in the higher socioeconomic areas for the various ethnic groups, an indirect way of testing the spatial assimilation model (Balakrishnan 1990; Balakrishnan and Kralt 1987). In a study limited to Toronto and Vancouver, Fong and Wilkes (1999) find that while the model works for the European groups, it does not for the visible minorities. They conclude that immigrants with darker skin color are less able to translate their socioeconomic resources into desirable neighbourhood environments (Fong and Wilkes 1999). In the United States, increases in income have only a moderate effect in reducing residential segregation for Blacks (Massey and Denton 1993; Logan, Stults and Farley 2004). It is clear that the social class or spatial assimilation model is not a simple explanation of segregation for all groups, but is complicated by other factors.

The second hypothesis states that ethnic residential segregation is due to the social distance among the ethnic groups. Social distance is revealed by acceptance of a different ethnic group members as work colleagues, neighbours, close friends or spouses. Greater social distance may be reflected in higher levels of residential segregation. Members of an ethnic group may avoid areas where another ethnic group is concentrated . Similarly, members of a certain group may live in proximity to avoid other members moving in. Studies on black-white segregation in the United States show clearly the importance of social distance (Lieberson and Waters 1988). In Canada, the few studies to date show that social distance is closely related to residential segregation (Balakrishnan and Hou 1999).

While the above two hypotheses stress the involuntary causes of segregation, the third hypothesis emphasizes the voluntary cause of segregation. It argues that 
persons of the same ethnic ancestry choose to live in proximity so that social interaction with other members of their group can be maximized (Clark 1992). An ethnic enclave provides the opportunity to form and sustain certain specialized institutions such as ethnic stores, entertainment places and restaurants. They also increase the chances of maintaining their heritage language and, in general, the values and norms of the group. For the new immigrants an ethnic enclave is a haven providing familiar surroundings, language and friendship in a new land. Often they get economic assistance and other resources that they may not get elsewhere. They may also find employment in the ethnic economy easier to get, especially if they are less skilled.

For this study we will focus on the social class and cultural identity hypotheses. It is interesting to note that for an immigrant these hypotheses work in conflicting ways. The desire for social mobility is universal and with increasing social class, the choice of places to stay widens. Hence, one would expect segregation levels to go down. At the same time, the need to maintain one's cultural identity would increase one's desire to live in an ethnic neighbourhood. Therefore as an immigrant's socioeconomic status increases, he or she is faced with dilemma of whether to stay in the same neighbourhood or move out. Those groups who feel strongly about their cultural identity may be reluctant to move from their ethnic neighbourhood even if their social mobility enables them to make such a move. Many western and northern European groups who came to Canada earlier were culturally close to the dominant groups of English and French, and probably did not feel the need to live in separate neighbourhoods. Thus, for example, we do not see Dutch, Scandinavian or German neighbourhoods in Canadian cities. These peoples quickly assimilated into the dominant culture. By the second generation, most of these European immigrants switched their home language to English. Moreover, with social mobility, there is also increased geographic mobility to better areas in the city.

Even southern Europeans such as the Italians, Portuguese and Greeks who often had distinct ethnic enclaves, moved to better areas with increases in their social status. Many of them were in lower socioeconomic classes when they came to Canada and had little choice than to move to segregated neighbourhoods. But their cultural closeness enabled these southern European immigrants to move more easily as their economic conditions improved. In contrast, the more recent immigrants who are mostly the visible minorities from Asia, are quite different in their cultural background. Apart from language, their values and customs in relation to the family, religion and other social institutions are substantially different from the prevalent Canadian culture. It is only natural that they will take a longer time to adapt to Canada. At the same time they are likely to get greater comfort in staying in their ethnic neighbourhoods. They are also 
more likely to experience discrimination due to their race and skin colour and may want to live in their own ethnic enclave. We hope to look at the relative importance of social class and cultural identity as factors in the residential segregation of various ethnic groups to see whether they follow the above observations.

The following hypotheses follow from the above discussion.

Hypothesis 1: Segregation is likely to be higher for the visible minorities than for the European groups.

Hypothesis 2: Segregation indices will decrease for the European groups with passing generations, but this will be less evident for the visible minorities.

Hypothesis 3: Segregation indices will decrease in the better socioeconomic areas of the city for the European groups, but not necessarily for the visible minorities.

The higher socioeconomic areas in Canadian cities are usually in the suburbs. The trend for most is to move from the centre of the city to the suburbs as one's social status improves. Although urban development and gentrification has had an effect in revitalizing the core and its attraction as a residential choice, the general pattern of movement to suburbia still persist. This hypothesis implies that, even in the suburbs, visible minorities are likely to be concentrated compared with the European groups. In other words, while the visible minorities move to the suburbs as their socioeconomic position improve they tend to develop new ethnic neighbourhoods in the suburbs. The predominantly Chinese areas in Scarborough and South Asian concentrations in Brampton are examples of wealthier suburban enclaves in Metropolitan Toronto.

\section{Data and Methods}

The data used in this study come from the 2001 census. The unit of analysis is a census tract. Census tracts are small geographic areas that usually have a population of a few thousand with a median of around 4,000 people. The census does not provide cross-classifications by ethnicity within a tract, a serious limitation of this study. Thus, we do not have data on variables such as income or education by ethnicity within a census tract.

A socioeconomic index (SES) for each census tract was constructed combining measures for three variables, education, income and occupation. It was assumed 
Social Class versus Cultural Identity as Factors in the Residential Segregation

of Ethnic Groups in Toronto, Montreal and Vancouver for 2001

that a combination of three variables indicates SES better than any one taken separately.

The three variables were operationalized as follows.

Education: Percent of adults over 25 years of age with university degree in the census tract

Income: Median family income in 2000 in the census tract.

Occupation: Percent employed in higher status occupations, namely, managerial, professional and technical occupations in 2001 in the census tract..

The three variables were first standardized to the same overall mean of 50 and standard deviation of 10 based on all the 4153 census tracts in the 23 Census Metropolitan Areas of Canada. The socioeconomic index (SES) for any census tract is then calculated by averaging its scores on occupation, education and income. Toronto had a mean SES index of 53.7 with the lowest quartile (25 percent) of the tracts having as SES index less than 47 and the upper quartile having an SES index greater than 58. Montreal had a mean of 47.1, with the first quartile at 42 and the third quartile 51. Vancouver had a mean of 52.0 with the first quartile 46.5 and third quartile 57.5. While Toronto and Vancouver were comparable in SES, Montreal was distinctly lower.

A summary measure, the Gini Index, is constructed to investigate concentration of a minority group in a city. It is derived from concentration curves, where the vertical axis is the cumulative percentage of the population in a particular ethnic group, and the horizontal axis is the census tracts arranged in decreasing order of the ethnic population. The Gini index is the ratio of the area between the curve and the diagonal to the area of the triangle above the diagonal line. Thus, the range for the index is from 0 to 1 , with those values indicating either no concentration or complete concentration. ${ }^{1}$

The measure of segregation we selected is the "index of dissimilarity," which measures the differential distribution of two groups. It is the sum of either the positive or negative differences between the proportional distributions of two populations. Though this index, has its own pros and cons, it is used here as it is the most widely used measure in the literature and, consequently, facilitates comparability. The index for any particular ethnic group is calculated by comparing its distribution over the census tracts with the rest of the population over the same tracts. When two specific ethnic groups are compared, it gives the measure of segregation between the two groups. The index ranges from zero to 
unity, indicating complete similarity or dissimilarity between the distributions of the two populations.

Multiple response complicates the construction of indices. The extent of multiple response varies greatly by ethnicity. It is high among the European groups but low among the visible minorities. The inclusion of "Canadian" as a valid response further muddies the issue. Some ethnic groups give "Canadian" as a response much more frequently than others. We have decided to use total response (single or multiple) to identify the ethnic population. Thus, if someone gives a response of "Italian" either singly or in combination with other responses, he or she is considered an Italian. Because of double counting, the totals will not add to the city total. For the purposes of this study, this is not considered too serious a problem, but we must be aware of this issue in the interpretation of the results. Using only single responses would have been a graver error because it would exclude such a large section of the population. Sizeable multiple response is a reality in the Canadian population and has to be acknowledged.

\section{Concentration of Ethnic Groups:}

An idea of concentration can be obtained by comparing the cumulative proportion of census tracts with the cumulative proportion of the ethnic population in those tracts. Census tracts in the three Census Metropolitan Areas were arranged in decreasing order of their ethnic population in 2001, and the cumulative proportions were calculated. Table 1 shows the extent of concentration, by presenting the proportion of tracts in which 50 percent of an ethnic group population is found. The table also gives the Gini Indices, which are very similar in their pattern.

There is a low concentration of persons of British and French origins in all the three cities. The Gini Index at .442 for the British in Montreal is much lower than for the other minority groups. They are even less concentrated in Toronto and Vancouver with Gini Indices of .375 and .315 respectively. Although the French are a smaller group in Toronto and Vancouver, they show little concentration. Earlier studies have also consistently shown that, except for areas close to Quebec, the French are remarkably assimilated spatially in the rest of Canada (Balakrishnan and Hou 1999; Balakrishnan 2000). Concentration is also low for the western, central and eastern European groups, though slightly higher than for the British. Because of their relatively large size, Italians are considered as a separate category. They are somewhat more concentrated than the other European groups, probably a function of their relatively more recent migration to Canada. Many of the Italians came after the second world war, while other 


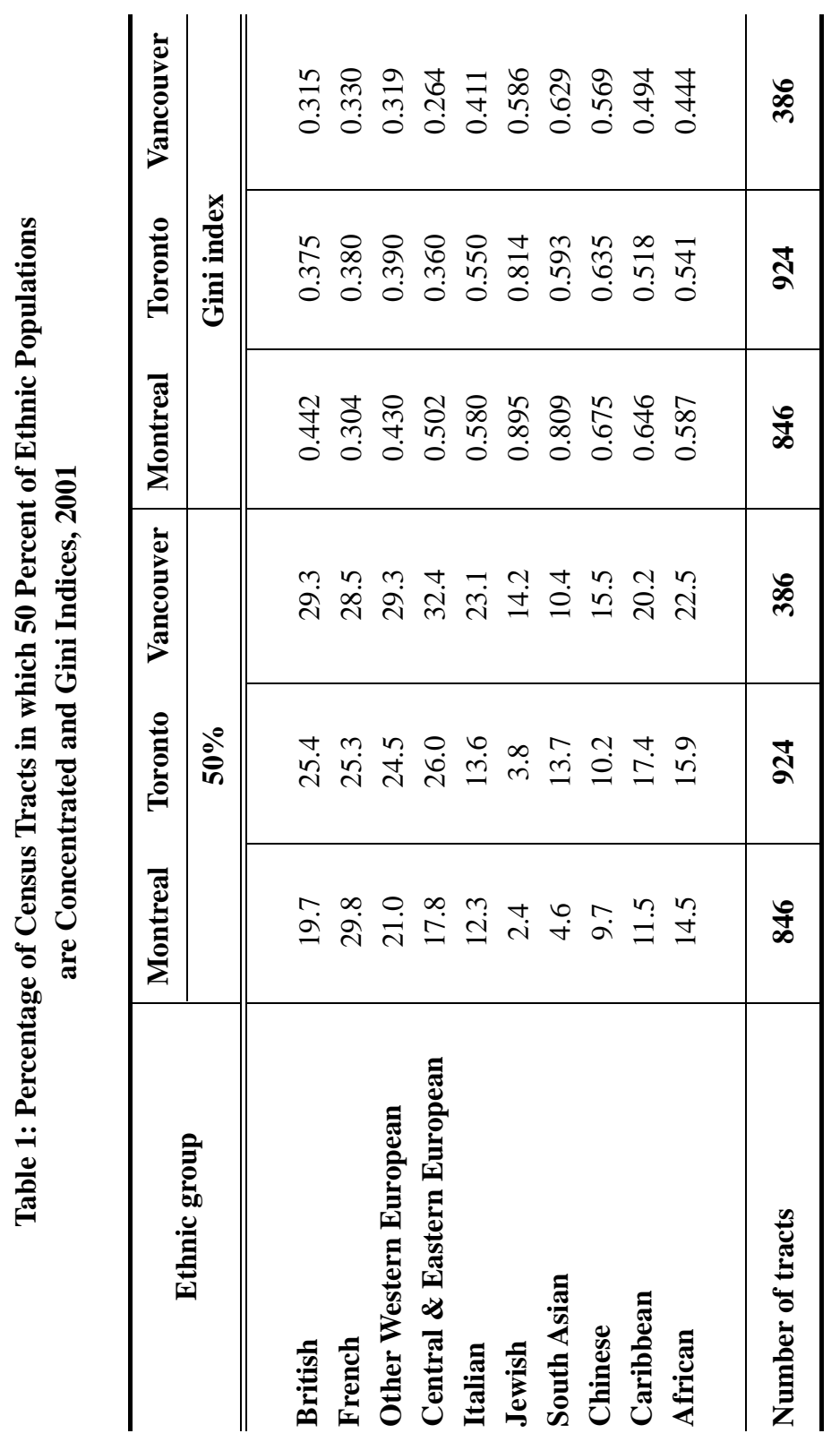


European groups such as the Germans, Dutch and Ukranians have a much longer history of migration to Canada Half of the Italians in Montreal live in 12.3 percent of the census tracts and, in Toronto, in 13.6 percent of the tracts.

Residential concentration is much higher for the other groups: Jews and visible minorities. The most residentially concentrated minority group in Canada are the Jews. Half of them lived in 2.4 percent of the tracts in Montreal, 3.8 percent of the tracts in Toronto and 14.3 percent of the tracts in Vancouver. The Gini Indices are also very high at .895 in Montreal, and .814 in Toronto, the two cities where most of the Jews in Canada reside. Jews tend to have a high socioeconomic status. Hence, their concentration cannot be attributed to a lack of social mobility, but rather to their strong cultural identity and the desire to live in close proximity to each other. For the more religious Jews, the location of a synagogue within walking distance may also be a factor. After the Jewish population, visible minorities are the next most concentrated groups in the three cities. In Montreal, half of the South Asians live in 4.6 percent of the tracts. They are less concentrated in Toronto and Vancouver, where the majority of them live. Half of the South Asians live in 13.7 percent of the tracts in Toronto and 10.4 percent of the tracts in Vancouver. The Gini Indices for the South Asians range from .593 in Toronto, to .629 in Vancouver and to .809 in Montreal. The Chinese show a somewhat lower concentration than the South Asians in Montreal, but in Toronto and Vancouver, their concentration is about the same. In spite of their large numbers, the Chinese in Toronto and Vancouver show substantial concentration. Half of the Chinese live in about a tenth of the tracts in all the three metropolitan areas, and their Gini coefficients of concentration vary from .593 in Toronto, to .629 in Vancovuer and to .809 in Montreal. The Black population, whether they are of African or Caribbean origin, show a significantly lower concentration than the other two major visible minorities of Chinese or South Asians, a striking difference from the U.S. residential patterns (Massey and Denton 1987). This may be because the Black population in Canada, unlike in the U.S, is a diverse population consisting of peoples from various Caribbean and African countries. Many Blacks in Canada have also lived here for many generations as opposed to recent immigrants from Asia. The cultural diversity among Canadian Blacks may be much higher than, say, the Chinese or South Asians.

How does one explain the lower concentration of European groups and the higher concentration of visible minorities in the metropolitan areas? Spatial assimilation or social class hypotheses would imply that visible minorities to Canada are recent immigrants; hence they lack the socioeconomic resources to locate other than in the poorer sections in the city core. However, this may not be the case. Many Europeans who also came recently, especially from Italy, Portugal and Greece, were less educated and in lower socioeconomic classes. 
Social Class versus Cultural Identity as Factors in the Residential Segregation

of Ethnic Groups in Toronto, Montreal and Vancouver for 2001

They subsequently became socially and geographically mobile. The level of segregation of many of these European groups has decreased over time. In contrast, the recent Asian immigrants are often more educated, many with having professional qualifications and being better skilled than the earlier European immigrants. Yet, we find that their segregation levels are much higher. While some of this higher level of segregation may be due to the social distance from the European groups, and discrimination in the housing market, we argue that their stronger cultural identity and social cohesion motivates them to live in ethnic neighbourhoods where they can maximize their contact with persons of their own background. In other words, the segregation of visible minorities may be due more to voluntary reasons rather than involuntary causes.

Figures 1 through 5 show the residential patterns of selected visible minority groups in Toronto and Vancouver. It is only a sample to illustrate that the traditional spatial pattern of new immigrants settling in the central core areas is longer true in Canada. In Toronto, most of the Chinese neighbourhoods are in the areas of Scarborough, Markham and Richmond Hill and less than $10 \%$ of Chinese neighbourhoods are in the old Chinatowns in the downtown area (Hou and Picot 2004). South Asians are concentrated in Scarborough, Mississauga and Brampton. The same patterns can be noticed in other metropolitan areas as well, where the minorities are located in other areas of the city including the suburbs and not necessarily in the core downtown areas. Another striking feature of the maps is that they show that ethnic neighbourhoods do not overlap to a great degree. Many minority groups are as segregated from each other as much as they are from the majority European groups (all the maps are not shown here due to lack of space). We may conclude that the concentration of minority groups in the three cities do not follow the old ecological patterns, but are more a function of earlier settlement patterns and their need for a location in proximity to others of their own ethnic origin. Besides, many minority groups are recent immigrants and hence may be attracted to ethnic enclaves. They would have to be observed for a longer time to assess whether they are more likely to migrate with increased duration of time in Canada. One way of investigating this possibility is to examine segregation by generations. If we assume that subsequent generations are likely to be upwardly mobile and more assimilated into the dominant Canadian culture, then they are less likely to be concentrated in the ethnic enclaves. 
T. R. Balakrishnan, Paul Maxim and Rozzet Jurdi

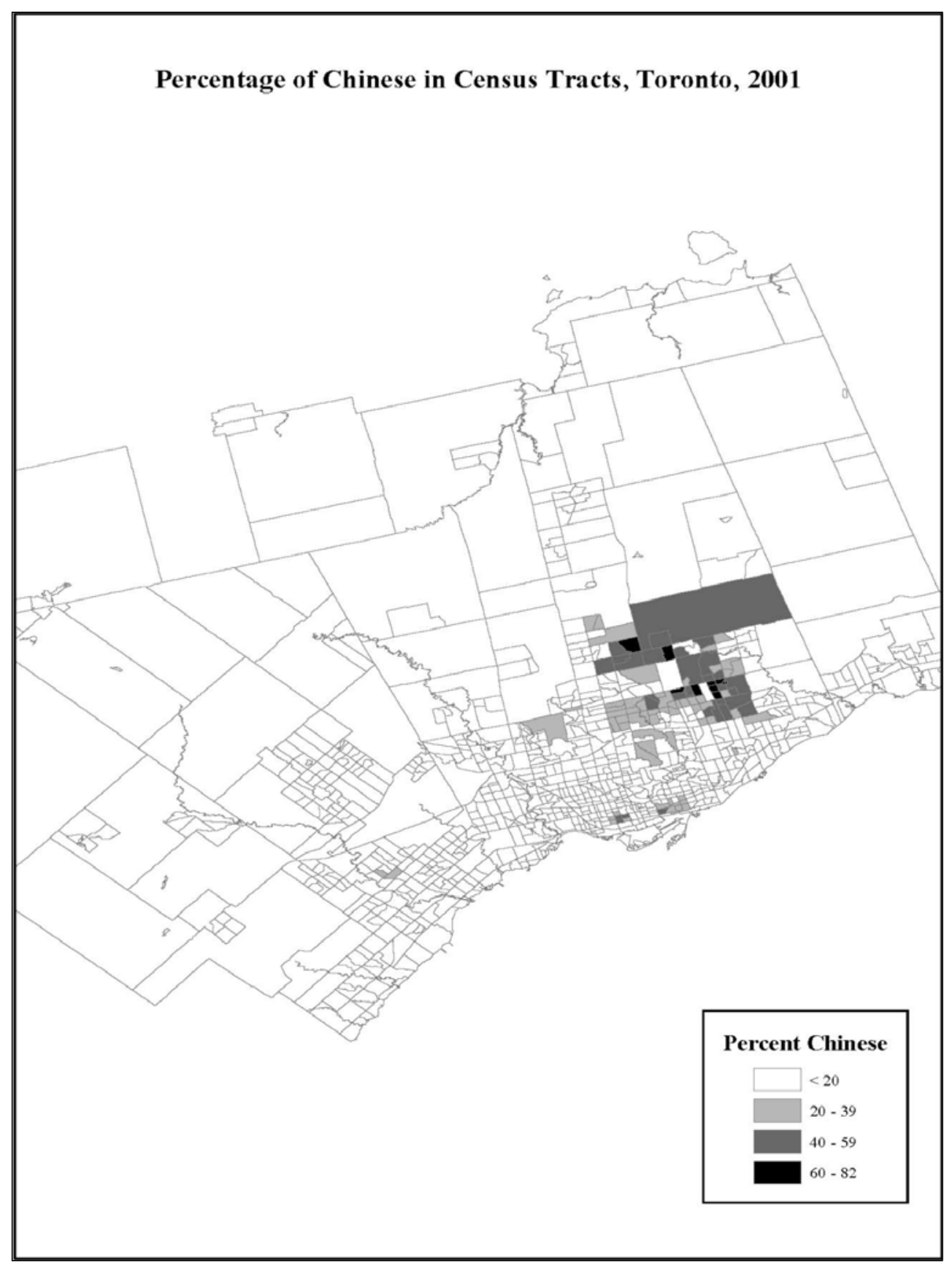


Social Class versus Cultural Identity on Factors in the Residential Segregation of Ethnic Groups in Toronto, Montreal and Vancouver for 2001

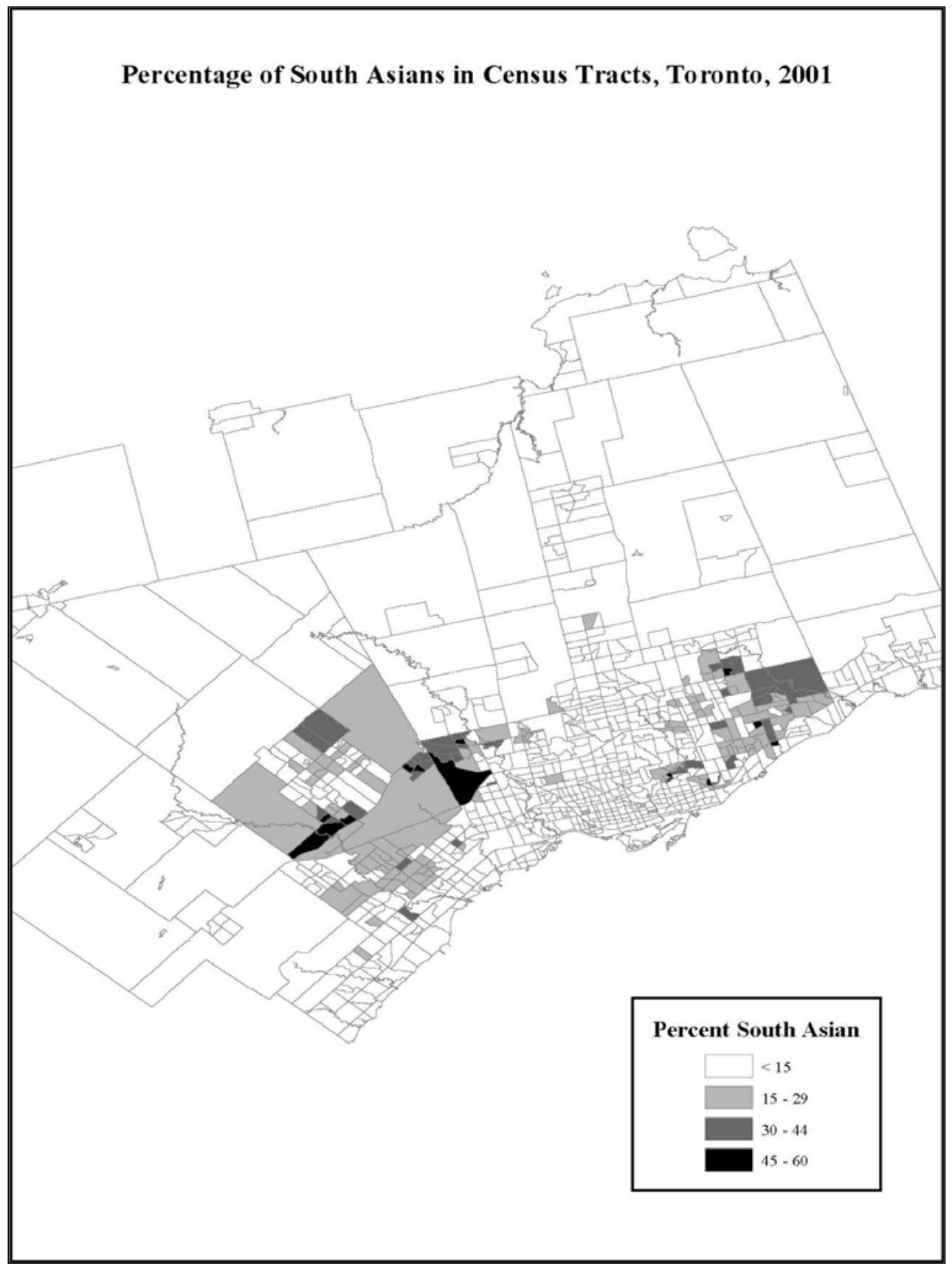


T. R. Balakrishnan, Paul Maxim and Rozzet Jurdi

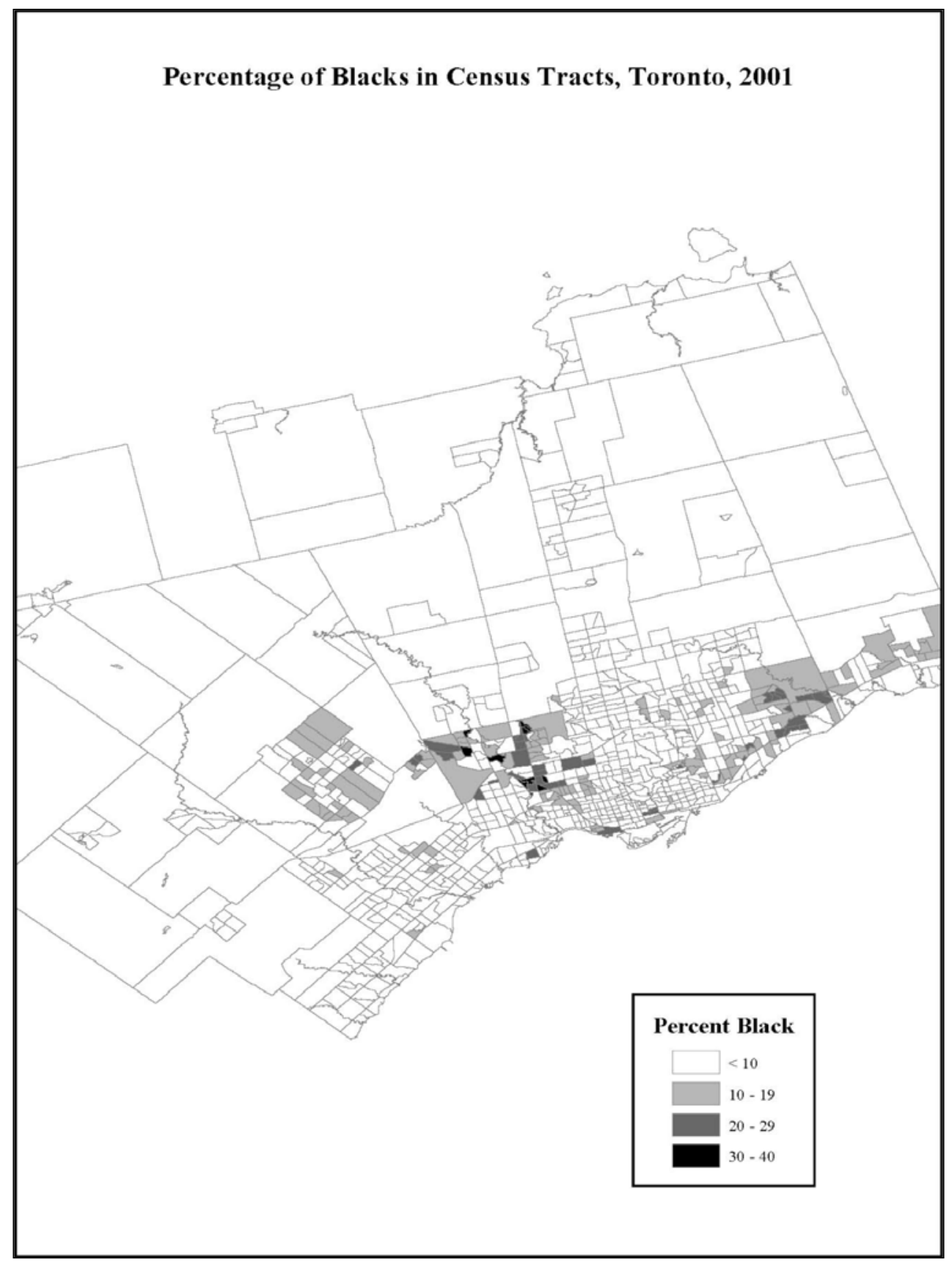


Social Class versus Cultural Identity on Factors in the Residential Segregation of Ethnic Groups in Toronto, Montreal and Vancouver for 2001

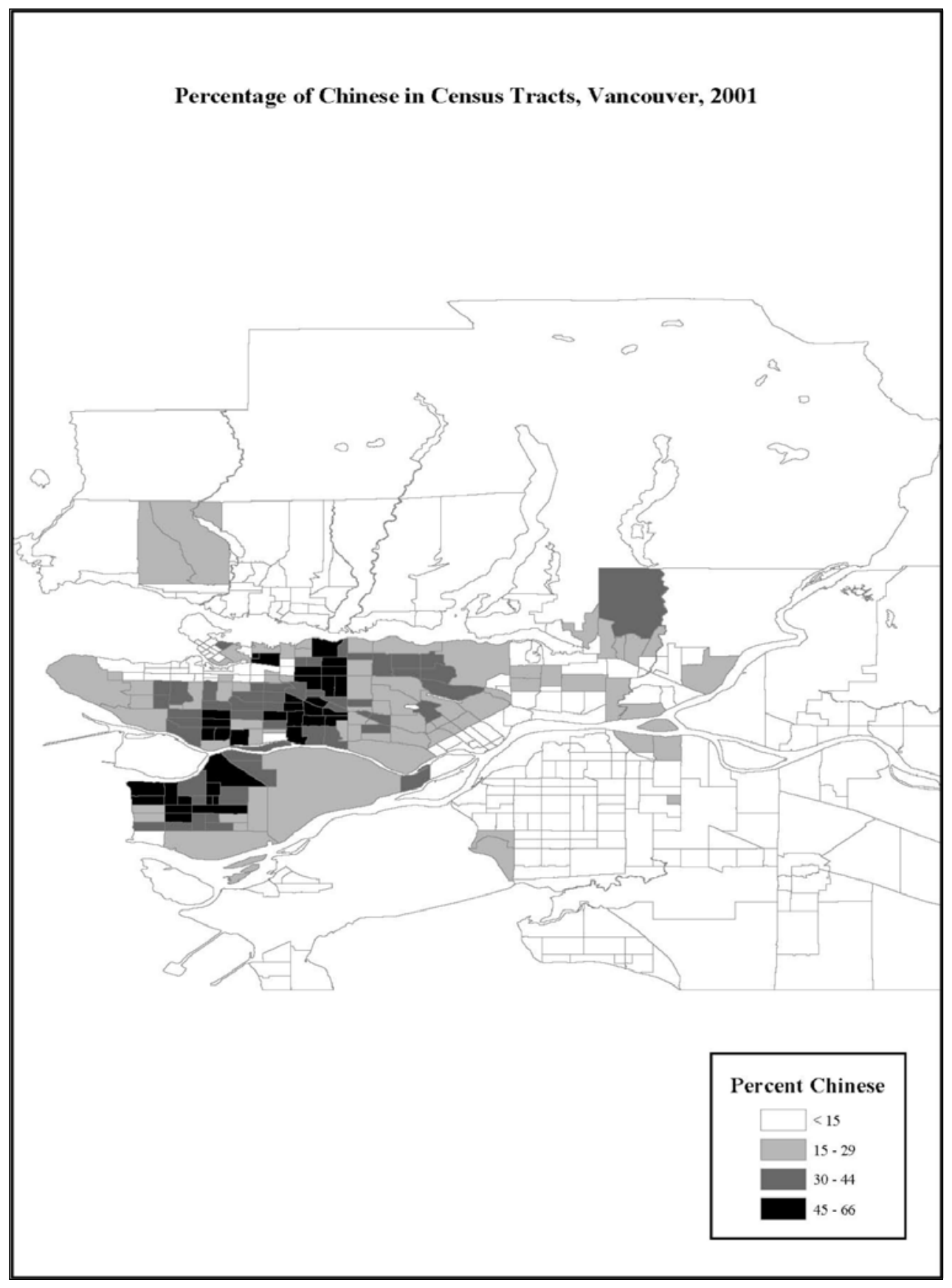


T. R. Balakrishnan, Paul Maxim and Rozzet Jurdi

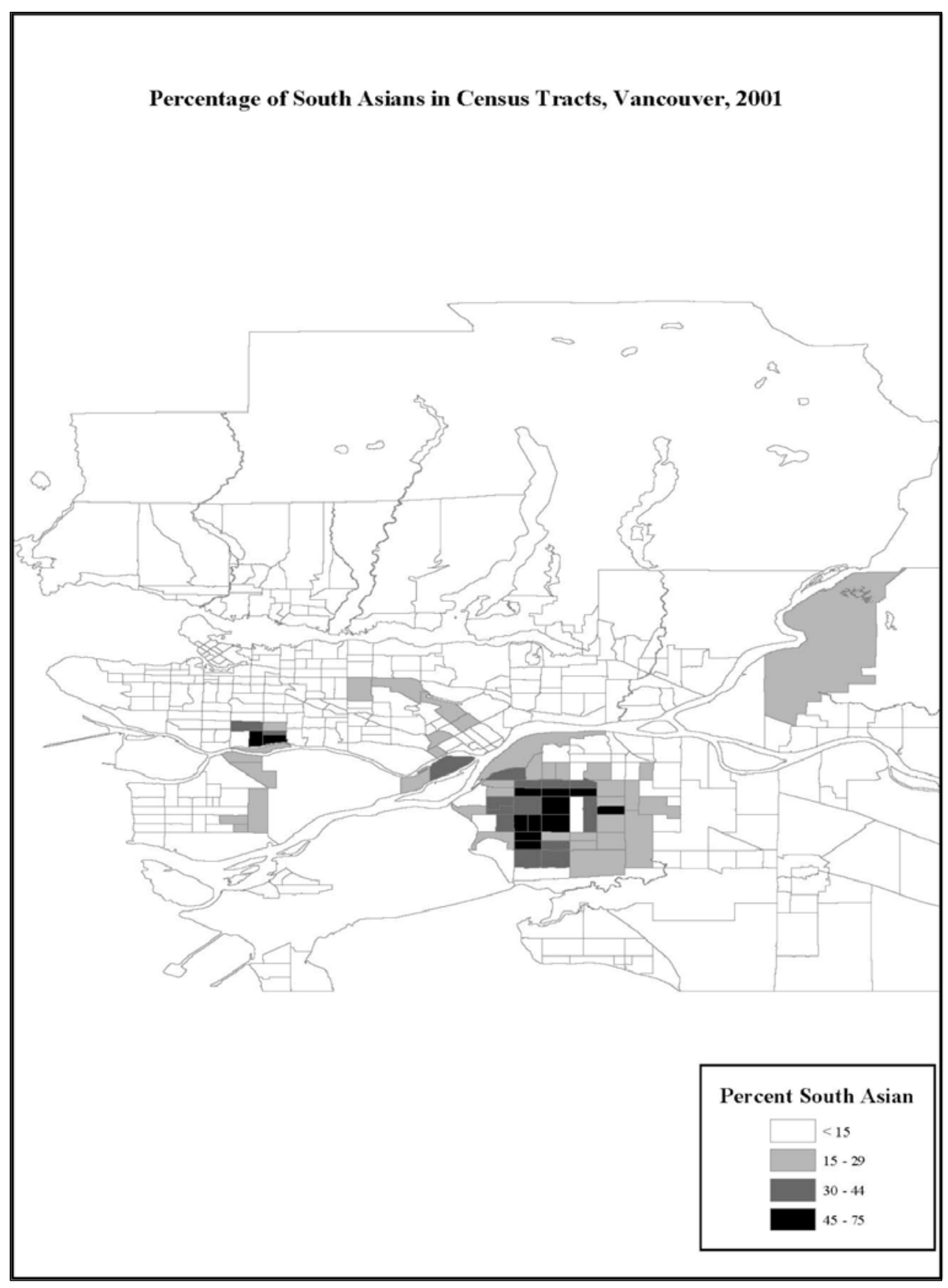


Social Class versus Cultural Identity as Factors in the Residential Segregation

of Ethnic Groups in Toronto, Montreal and Vancouver for 2001

\section{Segregation of Ethnic Groups}

When a minority group is concentrated geographically, it is more likely to be segregated from other groups. The correlation between Gini Indices of concentration and the segregation indices, measured by indices of dissimilarity, are always very high. Table 2 presents the segregation indices for selected ethnic groups for the three metropolitan areas. Just as with the Gini Indices of concentration, the segregation indices are highest in Montreal and lowest in Vancouver. In Montreal, it is not surprising that the French are the least segregated group. Their segregation index is only .184-the lowest for any group. Their substantial majority in the city and their dispersion across the city would explain this phenomenon. The British and western Europeans show relatively low levels of segregation 0.316 and 0.282 respectively. Jewish segregation has always been high in Montreal and continues to be so at .777 . The visible minorities exhibit high segregation, but show considerable variation among themselves, ranging from .636 for the Chinese to .426 for those of Caribbean origin. The segregation indices are somewhat lower in Toronto than in Montreal, but show the same pattern, low for the European groups but high for the visible minorities. Unlike in Montreal, South Asians in Toronto are more segregated than the Chinese. Blacks are noticeably less segregated than the Chinese or South Asians in both the cities, a dramatic difference from what is found in U.S.cities (Massey and Duncan 1987). Traditionally Vancouver had lower segregation indices than the other two major cities, but here again the pattern is similar, European groups having lower segregation and the visible minorities much higher segregation. Though the Chinese and the South Asians have large populations in Vancouver, and have a much longer history of residence there, show fairly high segregation with indices around .5. Blacks who are much smaller in number are fairly dispersed across the city and show a segregation index of only .3 .

\section{Segregation by Generations}

The spatial assimilation model implies that residential segregation is only a transitory stage for the new immigrant groups. In the beginning when they arrive to the new country they are forced to live in the poorer sections of the city often in the urban core. As their social mobility and acculturation to the host society increase, they move to the better areas of the city often in the suburbs. Thus one would expect with increased duration of stay in Canada, there would be desegregation or a decrease in the segregation levels. Residential segregation among the earlier immigrants should be less than the recent arrivals. By the same logic, one would expect the native born to be more assimilated than the foreign born and among the native born themselves, the segregation will 
T. R. Balakrishnan, Paul Maxim and Rozzet Jurdi

Table 2

Segregaion Indicies for Selected Ethnic Groups in

Montreal, Toronto and Vancouver for 2001

\begin{tabular}{l|c|c|c}
\hline \multicolumn{1}{c|}{ Ethnic group } & Montreal & Toronto & Vancouver \\
\hline \hline & & & \\
British & 0.316 & 0.364 & 0.290 \\
French & 0.184 & 0.272 & 0.206 \\
Other Western European & 0.282 & 0.292 & 0.216 \\
Central \& Eastern European & 0.409 & 0.303 & 0.142 \\
Italian & 0.432 & 0.403 & 0.257 \\
Jewish & 0.777 & 0.696 & 0.427 \\
South Asian & 0.520 & 0.509 & 0.494 \\
Chinese & 0.636 & 0.440 & 0.517 \\
African & 0.464 & 0.356 & 0.325 \\
Caribbean & 0.426 & 0.360 & 0.293 \\
& & & \\
\hline
\end{tabular}


Social Class versus Cultural Identity as Factors in the Residential Segregation

of Ethnic Groups in Toronto, Montreal and Vancouver for 2001

decrease with the third and higher generations. Segregation indices by generations are presented in Table 3. Because the population by ethnicity varies considerably by generation, the numbers are also presented in addition to the indices themselves. 2.5 generation refers to those who had one of their parents born in Canada. Indices based on small numbers will be unstable and should be interpreted with caution. For example, in Montreal, among the British, 71 percent are third generation, while among the South Asians only 1.2 percent are third generation, and among the Chinese 12.1 percent. Even in Vancouver, where there is a longer history of settlement of Chinese and South Asians, third generation Chinese amounted to only 11.9 percent and South Asians 16.8 percent of the population. While the European groups who came earlier to Canada are mostly native born, many new immigrants are primarily first generation, to a lesser extent second generation with very few in the higher generations.

The classic assimilation pattern, where successive generations show less residential segregation is found only among the European groups. Other west Europeans, central and eastern Europeans and Italians all show a decline with successive generations. The pattern in Toronto and Vancouver are basically the same as in Montreal, except that the indices in these cities are lower. In contrast, for the visible minorities, changes in segregation indices by generation provide little support for the assimilation hypothesis. Subsequent generations show as much segregation as the first generation of foreign born. For example, in Montreal, the segregation index for South Asians was .645 for the first generation, .754 for the second generations, and even higher for the third generation. Even though small numbers will exaggerate the index, the trend of non decline with generations is a significant finding. Similarly a small increase can be noticed among the Chinese as well, increasing from 0.558 for the first generation to 0.693 for the second generation.. The Black populations of African and Caribbean origin also show slight increases from the first to subsequent generations. In the other two cities of Toronto and Vancouver, there does seem to be a decline in segregation for the South Asians and Chinese. The finding of persisting segregation by generational status among many minority groups in Toronto has been noted earlier by Kalbach (Kalbach 1990). The most segregated group are those of Jewish origin, who have been in Canada for many generations yet show little sign of change in their segregation levels. 


\section{T. R. Balakrishnan, Paul Maxim and Rozzet Jurdi}

\begin{tabular}{|c|c|c|c|}
\hline$\equiv$ & 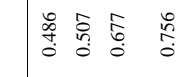 & 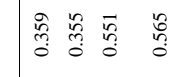 & 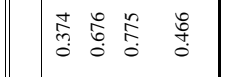 \\
\hline 商 & 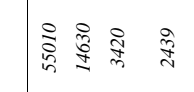 & 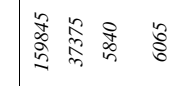 & 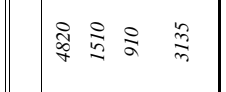 \\
\hline & 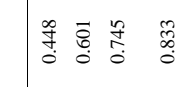 & 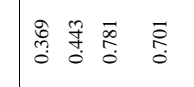 & 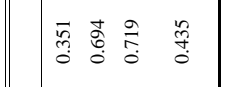 \\
\hline$\underline{\underline{z}}$ & 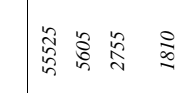 & 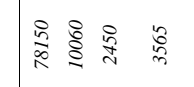 & 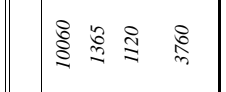 \\
\hline 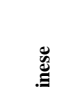 & 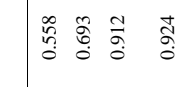 & 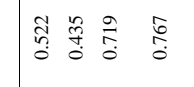 & 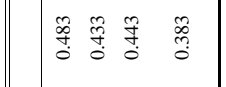 \\
\hline$\overline{\tilde{c}}$ & 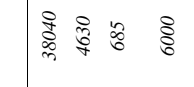 & 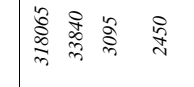 & 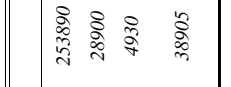 \\
\hline 高 & 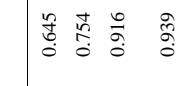 & 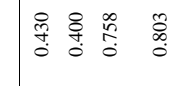 & 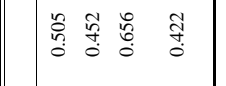 \\
\hline 訔 & 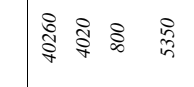 & 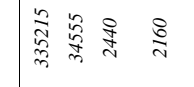 & 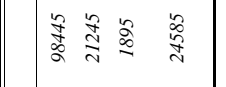 \\
\hline & 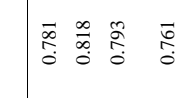 & 总 & 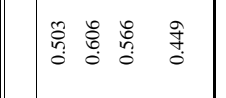 \\
\hline & 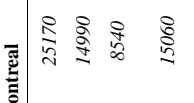 & 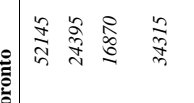 & 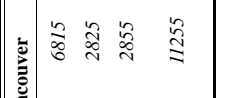 \\
\hline 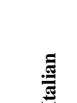 & 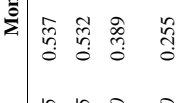 & 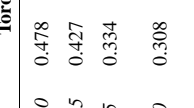 & 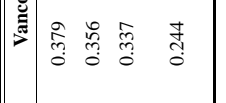 \\
\hline & 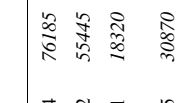 & 量善美善 & 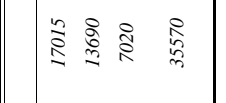 \\
\hline 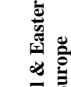 & 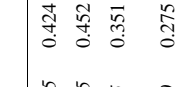 & 裹 동 & 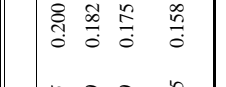 \\
\hline$\frac{z^{2}}{2 \pi}$ & 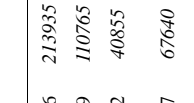 & 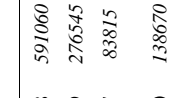 & 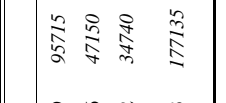 \\
\hline 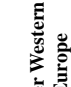 & 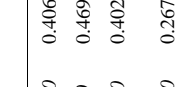 & 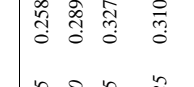 & 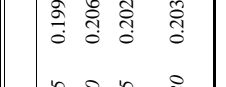 \\
\hline 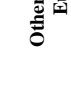 & 量最是高 & 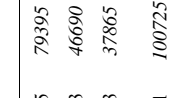 & 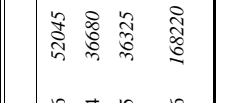 \\
\hline 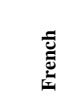 & 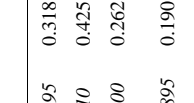 & 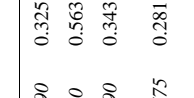 & 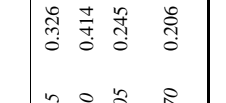 \\
\hline & 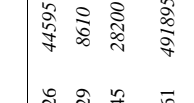 & 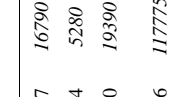 & 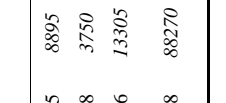 \\
\hline 童 & 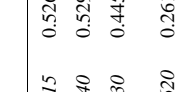 & 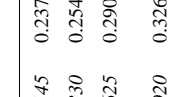 & 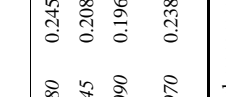 \\
\hline & 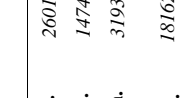 & 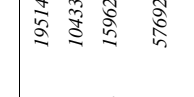 & \\
\hline & 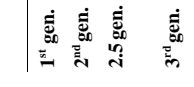 & 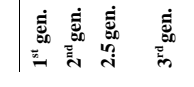 & $\mid$ \\
\hline
\end{tabular}


Social Class versus Cultural Identity as Factors in the Residential Segregation

of Ethnic Groups in Toronto, Montreal and Vancouver for 2001

The fact that segregation levels persist at higher levels even in subsequent generations for the visible minority groups, in spite of their social mobility and acculturalisation to the Canadian way of life, implies that their need for maintaining their cultural identity and close ties with members of their own group is strong enough to result in uniformly high spatial segregation. To what extent it is also due to discrimination in the housing markets and prejudice by other ethnic groups is something we cannot estimate from the census data, but should be explored.

\section{Ethnic Segregation and the Social Status of Neighbourhoods}

The Spatial assimilation model argues that ethnic segregation is largely due to social class differences among the ethnic groups and not because of the ethnic factor itself. The occupational, educational and income compositions of the ethnic groups differ and the observed segregation patterns are a manifestation of these basic differences which facilitate or hamper their ability to chose desirable places to live. This would mean that persons of the same social class are less likely to be residentially segregated even though they may belong to different ethnic groups. Some previous studies, however, have shown that even when social class is controlled, ethnic segregation persists (Darroach and Marston 1971; Balakrishnan 1982). When aggregate data at the census tract level are used, only a crude, indirect method can be employed to test the relationship between ethnic segregation and social class. The census tracts were grouped into four categories according to the socioeconomic status (SES) level of residents in those tracts. The groups were approximately equal in size containing a fourth of all the tracts in the city. Segregation indices for the various ethnic groups were constructed separately for each of the four sets of census tracts (Table 4). If persons of higher social classes are less likely to be segregated one would expect the segregation indices to decrease with increasing SES of the tracts. While there is a clear support for this hypothesis in Vancouver, the picture is far from clear in Montreal and Toronto. In Montreal, the segregation levels seem to persist across SES groups for most ethnic groups. Some exceptions are found among the Italians and South Asians. For Italians, the segregation index decreases from .505 to .316 and for South Asians from .728 to .546. In Toronto, those who show a decline are the western, central and eastern European groups. The visible minorities of Chinese, South Asians and Blacks show no decline with increases in SES. In other words, even in areas of higher SES, just as in the more affluent suburbs, they continue to be segregated. This is in line with maps which show concentration of minorities even in the areas away from the city centre. 
T. R. Balakrishnan, Paul Maxim and Rozzet Jurdi

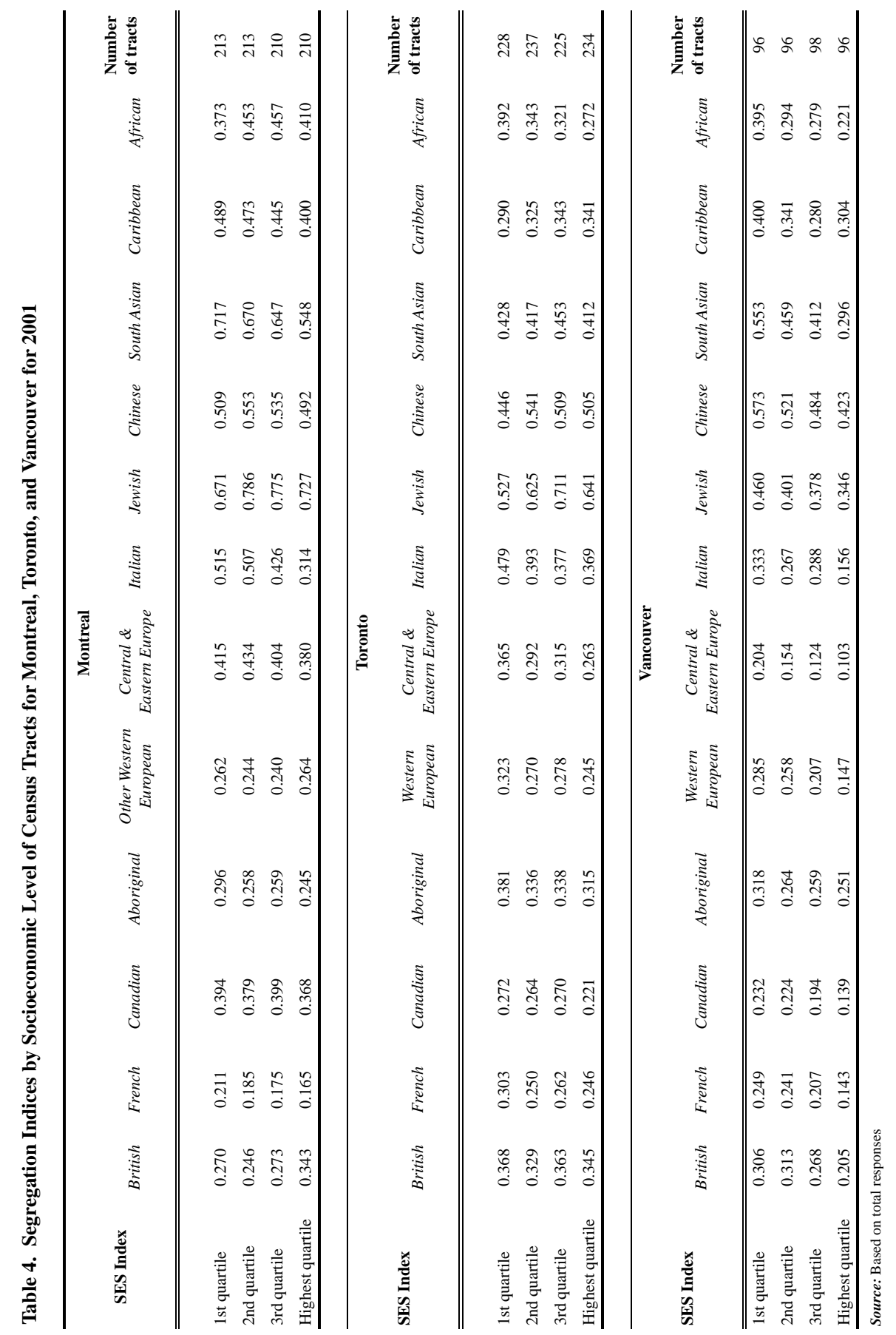


Social Class versus Cultural Identity as Factors in the Residential Segregation

of Ethnic Groups in Toronto, Montreal and Vancouver for 2001

\section{Conclusion}

Much of the traditional literature on urban segregation suggests that ethnic clustering is primarily a consequence of systematic discrimination and or poor socioeconomic resources. In many different times and places, this has clearly been the case. In the Canadian context, however, clear-cut systematic patterns of residential discrimination do not appear to hold. Instead, residential segregation often defies simple explanations based on either ethnic identity or socioeconomic background. While certain ethnic groups follow the classical assimilation pattern, others do not.

The preceding analysis strongly supports the assertion that Canada is increasingly becoming an open, pluralistic society where various groups may, or may not, choose to live in ethnically homogenous communities based on personal preference. This does not imply that ethnic and racial discrimination does not take place in the housing market. What it does imply, however, is that this is likely a minor factor in explaining people's residential choices. Residential choice appears to be more closely related to cultural preferences and ordinary market forces within the housing industry.

\section{End Notes:}

1. Our Gini Index should not be confused with the Gini coefficient (index) often mentioned in segregation literature. The latter is based on the socalled 'segregation curve', which is obtained by plotting the cumulative percentage of majority group against the cumulative percentage of minority group (Duncan and Duncan 1955). Thus it is a measure of segregation between two groups using areal units in its construction (Massey and Denton 1988).In comparison, the Gini Index used here is based only on the distribution of one ethnic group in space. It is a measure of spatial concentration of each group without being directly relative to another group. See Shryock and Siegel (eds)

The methods and materials of Demography. Condensed version by Edward Stockwell. Pp.98-99 for its construction The measure was called by its authors as Gini concentration ratio. 
T. R. Balakrishnan, Paul Maxim and Rozzet Jurdi

\section{References:}

Balakrishnan T.R. 1982. "Changing Patterns of Ethnic residential segregation in the metropolitan areas of Canada". Canadian Review of Sociology and Anthropology. 19(1). Pp. 92-110.

Balakrishnan T.R. 2000. "Residential Segregation and Canada's Ethnic Groups", in Kalbach and Kalbach (eds). Perspectives on Ethnicity in Canada. Pp.121-136. Toronto: Harcourt Canada..

Balakrishnan T.R. and John Kralt. 1987. "Segregation of visible minorities in Montreal, Toronto And Vancouver', in Leo Driedger (ed). Ethnic Canada: Identities and Inequalities. Pp. 138-157. Toronto. Copp Clark Pitman.

Balakrishnan T.R. and Selvanathan K.1990. "Ethnic residential segregation in metropolitan Canada", in Shiva Halli, Frank Travato and Leo Dreidger (eds). Ethnic Demography. Pp. 399-413. Ottawa. Carleton University Press.

Balakrishnan T.R. and Feng Hou. 1999a. "Residential patterns in Cities". In Shiva Halli and Leo Driedger (eds). Immigrant Canada. Pp. 116-147.

Burgess,E.W.1925.“ The Growth of the city: An Introduction to a research project”, in R.E.Park E.W.Burgess and R.E.McKenzie (eds). The City. Pp.47-62. Chicago .University of Chicago Press.

Clark, W.1986."Residential Segregation in American cities: A review and Interpretation", Population Research and Policy Review 5 Pp.95-127.

Darroch A.G. and Marston. W.G. 1971." The social class basis of ethnic residential segregation: The Canadian case". American Journal of Sociology. 77. Pp. 491-510.

Fong, Eric and Rima Wilkes. 1999. "An Examination of Spatial Assimilation Model”, International Migration Review 33(3): 594-620.

Hou Feng and Garnett Picot. 2004. "Visible minority neighbourhoods in Toronto, Montreal and Vancouver". Canadian Social Trends. Pp.8-13. Statistics Canada.

Joy, Richard. 1972. Languages in Conflict. Toronto. McClelland and Stewart. 
Social Class versus Cultural Identity as Factors in the Residential Segregation of Ethnic Groups in Toronto, Montreal and Vancouver for 2001

Kalbach, Warren. 1990. "Ethnic residential segregation and its significance for the individual in an urban setting." in Raymond Breton, Wsevolod Isajiw, Warren Kalbach and Jeffrey G.Reitz (eds). Ethnic Identity and equality: Varieties of experiences in a Canadian City. Pp. 92-134. Toronto. Toronto University Press.

Lieberson, Stanley.1970. Language and Ethnic Relations in Canada. New York. John Wiley and Sons.

Lieberson, Stanley. 1980. A Piece of the Pie : Blacks and White Immigrants since 1880. Berkeley. University of California Press.

Lieberson, Stanley and Waters, Mary. 1988. From Many Strands. New York,. Russel Sage Foundation.

Logan John R, Brian J.Stults and Reynolds Farley. 2004. " Segregation of Minorities in the Metropolis". Demography, 14. Pp. 1-22.

Massey, Douglas and Denton, Nancy. 1985. "Spatial assimilation as a socioeconomic outcome". American Sociological Review 50: 94-106.

Massey, Douglas and Denton, Nancy. 1987. "Trends in the Residential Segregation of Blacks, Hispanics and Asians: 1970-1980", American Sociological Review 52. Pp. 802-25.

Massey, Douglas and Denton Nancy. 1993.American Apartheid. Cambridge. MA. Harvard University Press.

Statistics Canada. 2003. Canada's ethnocultural portrait: The Changing ethnic mosaic. 2001 Census analysis series. Catalogue no.

96F0030XIE2001008. Ottawa. 